IOSR Journal of Pharmacy

e-ISSN: 2250-3013, p-ISSN: 2319-4219, www.iosrphr.org

Volume 2 Issue 6 || $\mid$ Nov-Dec. 2012 || $\mid$ PP.54-59

\title{
Role of sodium and potassium ions in identification of offspring gender in rats
}

\author{
S. CHANDRAJU* ${ }^{1}$, ASHRAF BEIRAMI ${ }^{1}$ AND C. S. CHIDAN KUMAR ${ }^{2}$ \\ ${ }^{I}$ Department of Studies in Sugar Technology, Sir M. Vishweshwaraya Post-Graduate Center, \\ University of Mysore, Tubinakere 571402, Mandya, Karnataka, India, \\ ${ }^{2}$ Department of Engineering Chemistry, Alva's Institute of Engineering \& Technology, Shobhavana \\ Campus, Mijar, Moodbidri-574225,South Canara Dt. Karnataka, India.
}

\begin{abstract}
Effects of Sodium and Potassium in diet to determine rats baby have been investigated.20 healthy rats chosen from the first generation of the previous experimented rats, were divided into two groups in the ratio male to female 1:5. The first group was $\mathrm{Na}$ and $\mathrm{K}$, the second group was control unit without $\mathrm{Na}$ and $\mathrm{K}$. It was found that the delivered offspring male to female ratio were 2.61:1 and 1.02:1 for the first and second groups respectively. Also, it was found that rats fed with (Na, K) food yields maximum numbers of male offspring 68, while rats fed with normal food yields lowest numbers of male offspring 48.
\end{abstract}

Keywords-Sodium, Potassium, Sex ratio, Wistar rat.

\section{INTRODUCTION}

Pregnancy is the fertilization and development of one or more offspring, known as an embryo or fetus, in a woman's uterus. In mammals, pregnancy is defined as the period between implantation of a fertilized egg (now called azygote) in wall of the uterus and delivery or other termination. The growth and development of the fetus in gestation is partially determined by the genome of the fetus, which produces its own growth factors as well as the majority of its hormones. However, this genetic influence is highly dependent upon interaction with environmental factors[1].

One environmental factor vital in the growth and development of the fetus is nutrition. A balanced, nutritious diet is an important aspect of a healthy pregnancy. Eating a healthy diet, balancing carbohydrates, fat, and proteins, and eating a variety of fruits and vegetables, usually ensures good nutrition. Those whose diets are affected by health issues, religious requirements, or ethical beliefs may choose to consult a health professional for specific advice. Adequate periconceptional folic acid (also called folate or Vitamin $\mathrm{B}_{9}$ ) intake has been proven to limit fetal neural tube defects, preventing spina bifida, a very serious birth defect. The neural tube develops during the first 28 days of pregnancy, explaining the necessity to guarantee adequate periconceptional folate intake[2,3].Folates are abundant in spinach (fresh, frozen, or canned), and are found in green leafy vegetables e.g. salads, beets, broccoli, asparagus, citrus fruits and melons, chickpeas and eggs. In the United States and Canada, most wheat products (flour, noodles) are fortified with folic acid [4].

DHA omega-3 is a major structural fatty acid in the brain and retina, and is naturally found in breast milk. It is important for the woman to consume adequate amounts of DHA during pregnancy and while nursing to support her well-being and the health of her infant. Developing infants cannot produce DHA efficiently, and must receive this vital nutrient from the woman through the placenta during pregnancy and in breast milk after birth [5].

The fetus is solely dependent on the mother to supply its nutrients. It is also dependent on the placenta, an essential organ in pregnancy, to transfer these nutrients from the maternal system to its own. Thus the fetal nutrition is a reflection of that of the mother's. This interaction exists in a sensitive equilibrium; if disturbed, there are fetal developmental consequences ${ }^{1}$.Preselection of the gender of offspring is a subject that has held man's attention since the beginning of recorded history. Although scientific studies on genes have been conducted recently, sex selection and gender preference have been considered since ancient time. Anaxagoras, a greek scientist was the first person who related the sex of fetus to testis [6].

There are many Methods of sex selection such as: The consumption of particular foods, the use of various vaginal douches and the timing of intercourse in relation to ovulation, Sperm sorting, Pre-implantation genetic diagnosis (PGD), Selective abortion, Infanticide, Periconceptual methods, postconceptual methods.

There are also methods which use different food combinations and especial diets to maximum the chance of having a baby with specific sex. The old believe is that eating salty, savory foods leads to delivering a 
male and sodium rich foods to a girl. Some believes that the ratios of the minerals sodium, potassium are important in determination of offspring gender. It was shown that pregnant female house mice maintained on a consistent low-food diet give birth to a lower proportion of males than do control females fed ad libitum[7].

As a part of our ongoing research, we studied the Role of Sodium and Potassium ions in identification of offspring gender in High-sugar mammals [8,9,10,11].

In this study, we study the effects of adding monovalent ions (sodium and potassium) to the drinking water of rats, offspring sexes was investigated.

\section{MATERIALS AND METHODS}

20 Adult female Wistar weighting 100-130g ,70-80 days old and still in their reproductive phase were kept under constant conditions of light (12 h light-dark cycle) and humidity, fed with standard laboratory chow ad libitum (Trouw, Gent, Belgium), and had free access to tap water. Before initiation, the rats were allowed to adapt for one week, then weighed. Vaginal wet smears were made to determine the estrous cycle of the rats. On the evening before oestrus, female rats were housed overnight with male rats; the presence of spermatozoa in a vaginal smear the next morning was defined as day one of pregnancy.

The data were entered and analyses by SPSS software using T-test and the p-value less than 0.05 were considered as significant.

\section{RESULTS AND DISCUSSION}

It was found that, in the first group mothers $(\mathrm{Na}, \mathrm{K})$; all of the 10 rats became pregnant which delivered 94 offspring. Their gender was 68 male $72.34 \%$ and 26 female $27.66 \%$. In the second group, Non (Na, K), all of the10 rats became pregnant and delivered 95 offspring, their gender was 48 male $50.52 \%$ and 47 female $49.48 \%$ (Table- 2).

The sex ratio of female to male in the first group of mothers $(\mathrm{Na}, \mathrm{K})$ was $2.61: 1$, While this ratio in the second group, non $(\mathrm{Na}, \mathrm{K})$ was1.02:1 respectively (Figs- 1 \& 2). The percentage of the male offspring of mothers $(\mathrm{Na}, \mathrm{K}) 72.345 \%$ was higher than the male offspring in control group $50.52 \%$ (Fig- 3).

The difference in the sex ratio between the first group mothers $(\mathrm{Na}, \mathrm{K})$ with control group were statistically significant (Table- 2).

The Total no of offspring in the first group mothers $(\mathrm{Na}, \mathrm{K}) 94$ was nearly equal to total no of offspring the control group 95 (Fig- 4).

Table- 1 Estimated Minerals Requirements.

\begin{tabular}{|lll|}
$\begin{array}{l}\text { Mouse } \\
\text { Minerals } \\
(\mathrm{g} / \mathrm{Kg})\end{array}$ & $\begin{array}{l}\text { Amount } \\
\text { diet( Kg })\end{array}$ & $\begin{array}{l}\text { Human *(mg- } \\
\text { ug/day) }\end{array}$ \\
\hline Calcium & 5.0 & 1000 \\
\hline Chloride & 0.5 & 750 \\
\hline Magnesium & 0.5 & $2-5$ \\
\hline Phosphorus & 3.0 & 700 \\
\hline Sodium & 0.5 & 500 \\
\hline Potassium & 2.0 & 2000 \\
\hline Iron & 35.0 & 8 \\
\hline Manganese & 10.0 & $2-5$ \\
\hline Zinc & 150.0 & $10-12$ \\
\hline Iodine & 150.0 & $150-150$ \\
\hline Molybdenum & 150.0 & $75-250(\mathrm{ug})$ \\
\hline
\end{tabular}

**adapted from Nutrient Requirements of Nonhuman Primates.

* Adapted from Lanus Micronutrient information Center, Oregon State Unit. 
Table- 2 Sex ratio in different groups of rats

\begin{tabular}{|lllllll|}
\hline Group & $\begin{array}{l}\text { Total no } \\
\text { of } \\
\text { offispring }\end{array}$ & $\begin{array}{l}\text { No. of } \\
\text { male } \\
\text { offspring }\end{array}$ & $\begin{array}{l}\% \text { age of } \\
\text { male } \\
\text { offspring }\end{array}$ & $\begin{array}{l}\text { No. of fispring } \\
\text { female }\end{array}$ & $\begin{array}{l}\% \text { age } \\
\text { female } \\
\text { offspring }\end{array}$ & $\begin{array}{l}\text { Sex } \\
\text { ratio }\end{array}$ \\
\hline $\begin{array}{l}\text { (Na, K) } \\
\text { Non }\end{array}$ & 94 & 68 & 72.34 & 26 & 27.66 & 2.61 \\
\hline (Na, K) & 48 & 50.52 & 47 & 49.48 & 1.02 \\
\hline
\end{tabular}

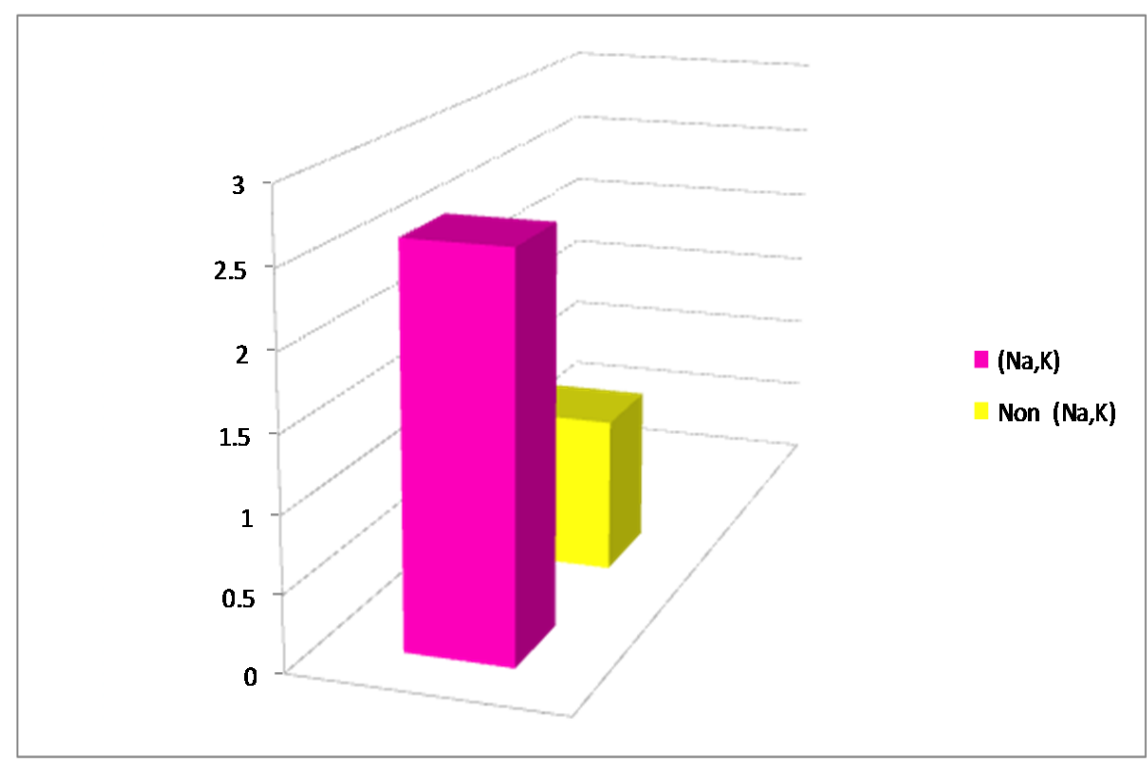

Fig-1 Male and female in different groups of rats

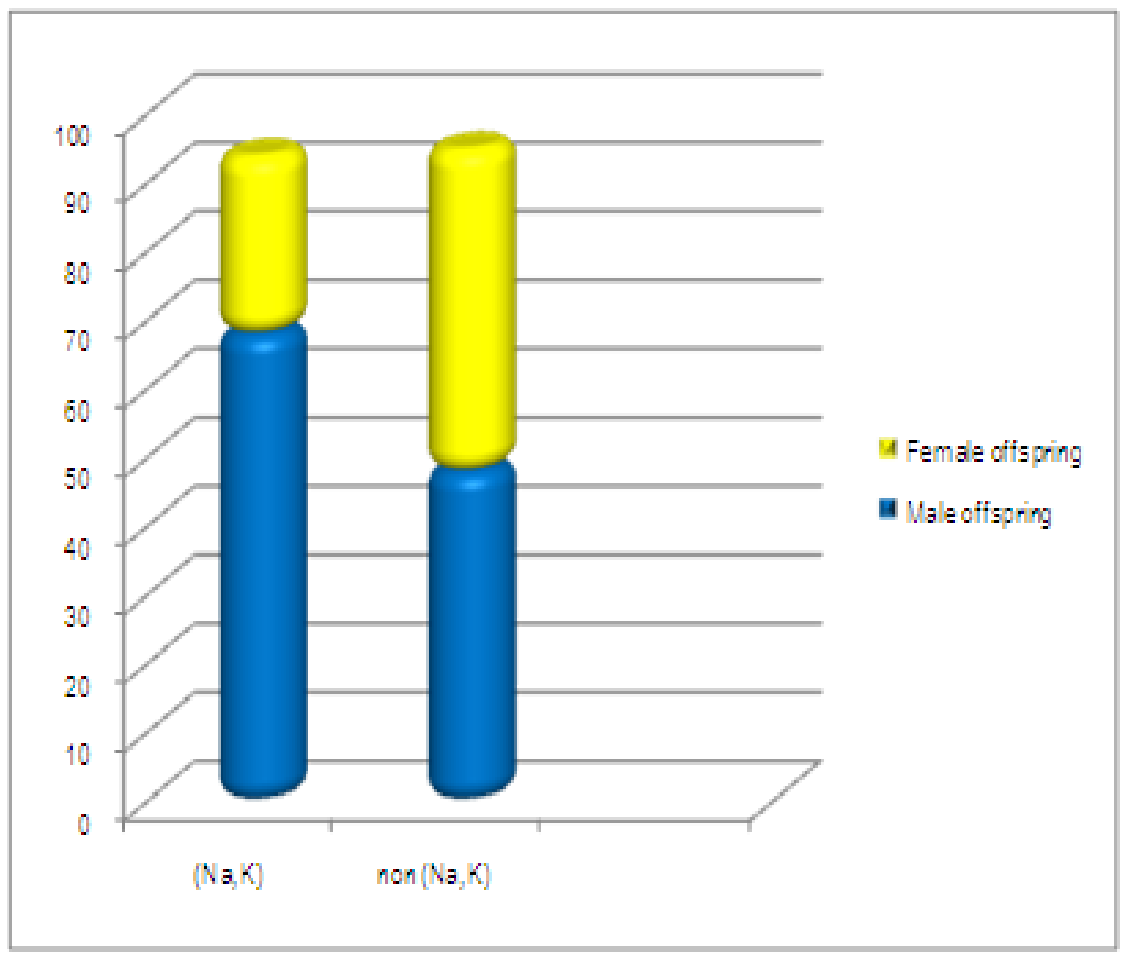

Fig- 2 Male and female in different groups of rats 


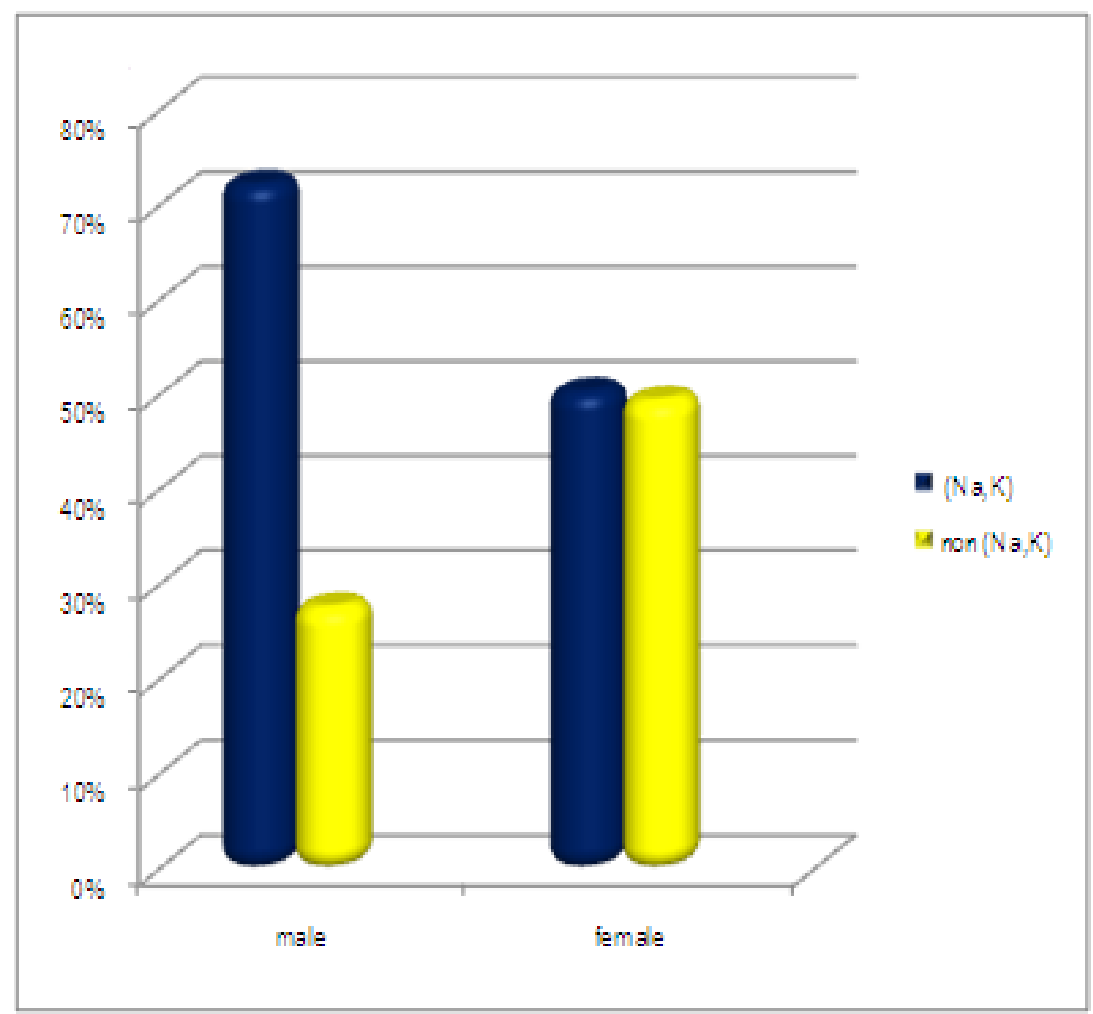

Fig- 3 Offspring sex in different groups of rats

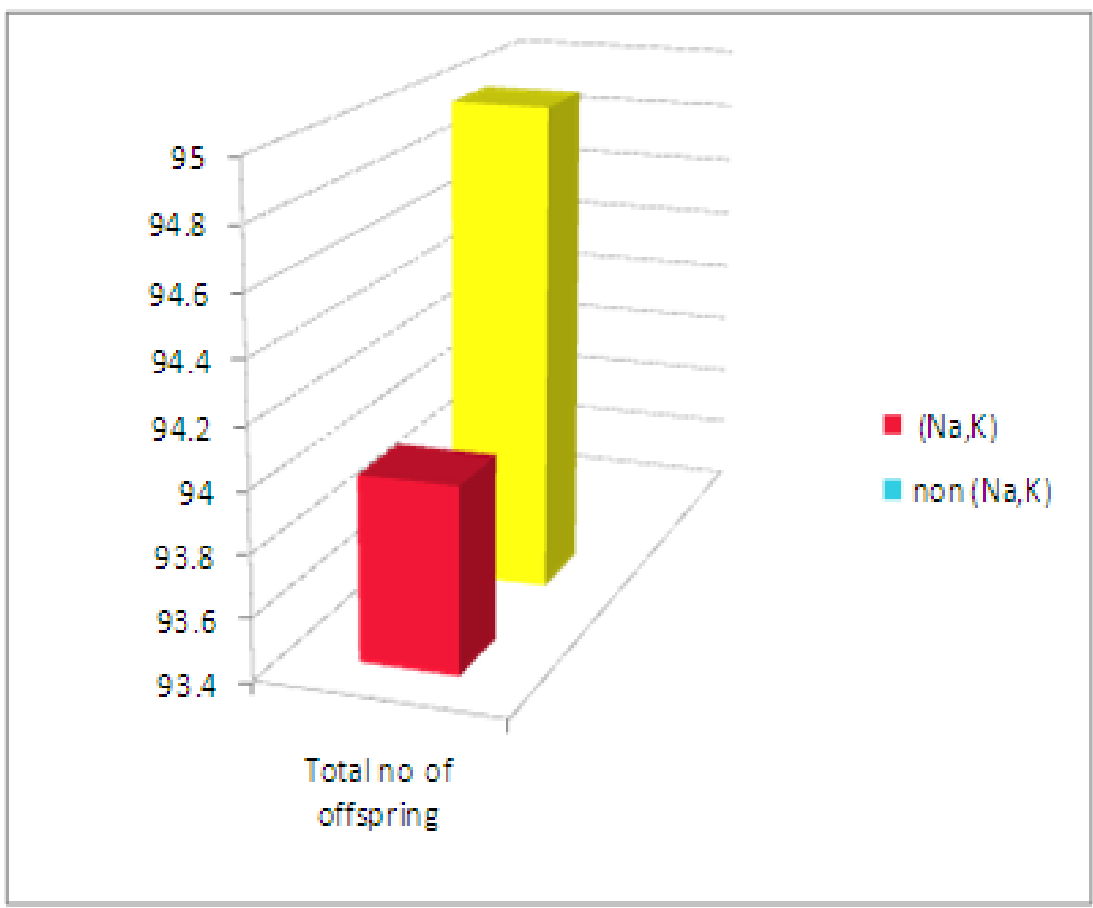

Fig-4 Number of offspring in different groups of rats

The first medical technique that can be used to select for sex is that of pre-natal diagnosis [PND] and abortion. To utilize this method, the pregnant woman must undergo some sort of prenatal testing, such as an amniocentesis, chorionic villus sampling or an ultrasound, which will allow the doctor to determine the sex of the child, among other things. Once the woman has the information about the child's sex, she Nan obtains an abortion if the fetus is not of the desired sex. The use of PND and abortion in order to select for sex sounds extreme, and indeed, as Edgar Dahl points out, it is not common for Westerners to utilize such a technique. For example, a follow-up study of 578 patients having prenatal diagnosis at one Melbourne centre found that none 
of the women had a termination because of the sex of the fetus .Going through the traumatizing experience of an abortion is usually seen as too high a price to pay for a child of a particular sex[12].

The second medical technique that can be used to select for sex is that of pre-implantation genetic diagnosis [PGD] with in vitro fertilization [IVF]. With this technique, the embryos are screened for sex prior to being implanted into the woman's uterus, thereby eliminating the need to later decide to terminate a pregnancy. PGD and IVF, however, are very invasive and potentially physically harmful, requiring the woman to go through at least one IVF cycle, which includes taking potent drugs to induce super-ovulation, extraction, fertilization and then testing and subsequent implantation of the embryos. Given the expense of IVF treatment cycles (according to IVF canada in 2005 it cost $\$ 5,500$ for one cycle of IVF, not including drugs[13].and, according to the same source, the drugs themselves Nan cost approximately $\$ 3,000$ for one cycle[14], it would be highly unlikely that it would be used as a technique for sex selection alone. More likely, it could be used as a sex selection technique for those who are already undergoing IVF for other medical reasons.

The last medical technique that can be used to select for sex is sperm sorting. New technologies allow sperm to be sorted into those carrying X or Y chromosomes with varying degrees of accuracy. To date, the most successful way in which to sort sperm is flow cytometry, which has been branded as the Micro Sort technique[15]. Sex selection using flow cytometry results from distinguishing between the identifiable differences between the $\mathrm{X}$ and $\mathrm{Y}$ chromosomes, as the $\mathrm{X}$ chromosome is larger than the $\mathrm{Y}$. The sorted sperm is then used to artificially inseminate the woman. Studies have shown that the Micro Sort technique is more effective in selecting for girls, a success rate of $91 \%$, than for boys, with a success rate of only $76 \% .12 \mathrm{Sperm}$ sorting appears, then, to be the least invasive and least expensive (at about $\$ 2,300 \mathrm{US}$ per cycle13) method of selecting for sex.

There are also methods which use different food combinations and especial diets to maximum the chance of having a baby with specific sex. The old believe is that eating salty, savory foods leads to delivering a male and sodium rich foods to a female. Some believes that the ratios of the minerals sodium, potassium are important in determination of baby gender. It was shown that pregnant female house mice maintained on a consistent lowfood diet give birth to a lower proportion of males than do control females fed ad libitum[16].

\section{CONCLUSION}

Today one of good known methods on sex constitution is the preconception diet method. This method claims $80 \%$ accuracy and the theory is that by altering your diet to include and exclude certain food, the condition in the reproductive tract will be directly affected; increasing the odds of conceiving a particular sex it is also recommended that both mother and father go on the diet. This is also consistent with the oriental philosophy that everything has a yin or yang quality and the foods supplied in the female diet, female and acid are all yin. The female diet is high in sodium but low in salt and potassium, containing acid forming foods. The diets nutritional content is questionable and contains multiple warnings. The diet may influence the conditions within the reproductive tract and the outer barrier surrounding the ovum. Enabling only one of the two types of sperm to penetrate the depending on which diet is adhered to. Langendon and Proctor first published 'the preconception Gender Diet `based on results reported [17].

The theory is that by altering your diet to include and exclude certain foods, the conditions in the reproductive tract will be directly affected, increasing the odds of conceiving a particular sex. This method under scrutiny claims of $80 \%$ accuracy based on one clinical trial of only 260 women, the results were published in the international journal of Gynecology and Obstetrics in 1980. The female diet is high in sodium but low in salt and potassium, aontaining acid forming foods. The diets nutritional content is questionable and contains multiple warnings.

It is recommended to seek the advice of medical practitioner before going on such a restrictive diet, and stay on the diet for no longer than 3 months. The diet may influence the condition of the cervical mucus and within the reproductive tract and follicular fluid. Enabling only one of the two types of sperm to penetrate the egg depending on which diet is adhered to. The aim of this study was to elevate relationship between minerals and sex ratio in rats.

\section{ACKNOWLEDGEMENT}

Authors are grateful to the Dean, Veterinary college of Bangalore for providing the facilities. 


\section{REFERENCES}

[1]. Van Assche F, Holemans K , and L.Aerts. Long-term consequences for offspring of diabetes during pregnancy. British MediNal Bulletin. 2001; 60; 173-182.

[2]. Klusmann A, Heinrich B, Stöpler H, Gärtner J, Mayatepek E, Von Kries R. 2005. "A decreasing rate of neural tube defects following the recommendations for periconceptional folic acid supplementation". Acta Paediatr. 94 (11): 1538-42.Doi:10.1080/08035250500340396. PMID 16303691. Retrieved 2008; 01-20.

[3]. Stevenson RE, Allen WP, Pai GS, Best R, Seaver LH, Dean J, Thompson S. 2000. "Decline in prevalence of neural tube defects in a high-risk region of the United States". Pediatrics 106(4);67783.doi;10.1542/peds.106.4.677. PMID 11015508.

[4]. Centers for Disease Control and Prevention (CDC) "Use of supplements containing folic acid among women of childbearing age_United States. 2007".MMWR Morb. Mortal. Wkly. Rep.2008; 57; 1: 5-8.PMID 18185493.

[5]. Salem, Jr. N, et al. Mechanisms of action of docosahexaenoic acid in the nervous system. Lipids.200 ; 36; 945-59.

[6]. Mittwoch U .Sex in mythology and history. Arq Bras Endocrinol Metab. 2005; 49; 7-13.

[7]. Meikle D.B and Thornton M.W. Premating and gestational effects of maternal nutrition on secondary sex ratio in house mice. J. Reprod.Fertil.1995; 105; 193-196.

[8]. Chandraju S, Beirami A and C.S. Chidan Kumar. Role of Sodium and Potassium ions in identification of baby gender in High-sugar mammal's .International Journal of Pharmacy and Pharmaceutical Sciences. 2011; 3; 4; 303306.

[9]. Chandraju S , Beirami A , C.S. Chidan Kumar.Effect of calcium and magnesium ions in identification of baby in High-sugar mammals .Research in Biotechnology.2011;2(3);23-31 .

[10]. Chandraju S, Beirami A. , C.S. Chidan Kumar. Effect of Sodium and Potassium ions in identification of baby in High-sugar hamesters.Research in journal of pharmaceutical and clinical research .2012; 5(1); 134-136.

[11]. Chandraju S, Beirami A, C.S. Chidan Kumar. impact of calcium and magnesium ions in identification of baby gender in High-sugar hamsters. Research injournal of pharmaceutical sciences and research .2011;3(12);16191624.

[12]. Visaria P.The sex ratio of the population of India and Pakistan and regional variations during 61. In: Bose A, editor. 1951. Patterns of population change in India 61. Allied Publishers .1967; 334-71.

[13]. Dahl E, Procreative Liberty. The case for Preconception Sex Selection.7Reproductive BioMedicine.2003; 380

[14]. Online: IVF Nanada from http://www.ivfcanada.com/services/fees/general_fee_schedule.cfm.

[15]. Steinbock, supra note 7 at 24.

[16]. Meikle D.B and M.W. Thornton. Premating and gestational effects of maternal nutrition on secondary sex ratio in house mice. J. Reprod.Fertil. 1995; 105; 193-196.

[17]. Stolkowskowski J and J.Lorrain.preconceptional selection of Fetal Sex.int. J.Gynaecol. Obstet.1982; 18; 440-3. 